\title{
The Design of Piezo-driven mirror for the Path Length Control in a Ring Resonator
}

\author{
Lee Jeong Ick $^{1^{*}}$ \\ ${ }^{1}$ Dept. of Mechanical Design INHA Technical College \\ 링 공명기의 경로치 제어를 위한 피에조 구동 거울의 설계 \\ 이정익 ${ }^{*}$ \\ ${ }^{1}$ 인하공업전문대학 기계설계과
}

\begin{abstract}
The principal operation of a ring laser gyroscope depends on the phase difference for the counter-propagating waves within a closed path. The reflection mirrors mounted on the resonator block form the traveling waves. Thus, the dimension accuracy of resonator block influences the traveling path of beam. In order to maintain the stable optical beam path in the ring resonator, the piezo-driven moveable mirror is adopted for the path length control under the thermal expansion or mechanical strain of resonator block.

This paper presents the mathematical description of the elastic behavior of piezo-driven mirror. This description can be applied for the concept design of piezo-driven mirror.

요 약 링 레이저 자이로스콥의 주 동작은 폐경로 내의 상대 전파에 대한 위상 차에 의존한다. 공명 블록위에 설치 된 반사경들이 순항 파를 형성한다. 따라서, 공명 블록의 차원 정확도가 빔의 순항 경로에 영향을 미친다. 링의 공진 내에서 안정된 광학 빔 경로를 유지하기 위해서 피에조로 구동되는 이동거울이 공명 블록의 열팽창이나 기계적 변형 하에서 경로치 제어를 하고자 선택되었다. 이 논문에서는 피에조 구동 거울의 탄성거동에 대한 수학적 설명을 제시하 였다. 이 설명은 피에조 구동 거울의 개념 설계에도 적용될 수 있다.
\end{abstract}

Key Words : Ring resonator, Resonator block, Piezo-driven mirror, Path length control

\section{Nomenclature}

L Resonator length

Scf Scale factor

$\Delta T \quad$ Temperature variation

$\alpha \quad$ Linear thermal expansion

$w_{i} \quad$ Displacement of piezo-driven $i$ part

$P \quad$ Static load in an equilibrium state

$p_{0} \quad$ Pressure due to piezo ceramic transducer

$g_{i} \quad$ Stiffness of piezo-driven $i$ part

$\sigma_{r}, \sigma_{\theta}$ Stresses inside the circular plate

$\varepsilon_{r} \quad$ Radial strain

\section{Introduction}

Ring lasers have been investigated in order to ascertain their suitability for use as rotation rate sensors. When there is an applied rotation about the axis normal to the plane of rotation, the operation of gyroscope depends on the phase difference for beams traveling in opposite direction within a closed path. This phase difference gives rise to other phase difference. But the accuracy of gyroscopes have been limited by the lock-in region due to the fact that at low rotation rates of gyroscope the frequency coupling mechanism arises from back scattering of the mirrors. This effect gives no phase difference and hence no detect of angular increment. In other words, this reduces the angular sensitivities to the electrical

"Corresponding Author : Lee, Jeong-Ick(jilee@inhatc.ac.kr) 
and mechanical disturbances such as low frequency noise components, in the optical measurement. It is important to minimize the transition periods of lock-in region. A good laser gyro consists of mirrors with low back scatter in conjunction with a stable gas discharge, a suitable dither drive, and a stabilized resonator cavity length in order to avoid temperature effects. Under the temperature effects, a change of the beam path increases the lock-in threshold. It is very important to stabilize the beam path during the operations ${ }^{[1,2]}$. By means of the piezo-driven mirror, it was possible to change the beam path inside the laser cavity with extreme precision. After the discovery of the lock-in effect, the interest of all those involved in development work began to concentrate on the theoretical definition and practical solution of this problem ${ }^{[3-6]}$. But, based on the beam path without the geometric consideration of piezo-driven mirror, a theory has been presented which describes the lock-in threshold as a function of the path.

This paper presents the geometric model of piezo-driven mirror. All parts of assembly can be described in the geometric dimensions. Thus, these geometric descriptions are very important for deciding the basic dimensions of parts, according to the piezo-driven mirror displacement.

\section{Effect of resonator geometry on the lock-in threshold}

The conventional laser gyroscope comprises three or four mirrors that are attached to the resonator block made of glass-ceramic material with ultra low thermal expansion.

Two-dimensional resonator plane is defined by the three reflection points on the mirror surfaces. The total resonator length is a sum of the distances between these reflection points. Fig. 1 shows the basic configuration of ring laser gyroscope and geometrical change of the ring resonator shape due to thermal expansion and path length control. Although the resonator length is stabilized by means of a movable mirror to an integral number of wavelengths, the individual distances between the reflection points may vary due to the block temperature. This mechanism changes the distribution of the scattering sources, the amplitudes of the back scatter wave trains and lock-in threshold.

Besides the variations of the beam path caused by temperature, mechanical strain, one has to take into consideration the manufacturing tolerances of the resonator block and inaccuracies during the assembling which will also influence the beam path position and the lock-in threshold. This is the reason why laser gyro manufactures complain about the poor reproducibility of the gyro characteristics.

The reflection mirrors form an optical resonator, whose the circumference (resonator length) $L$ is an integer number $m$ of the used wavelength.

$$
L=m \lambda=m(c / v)
$$
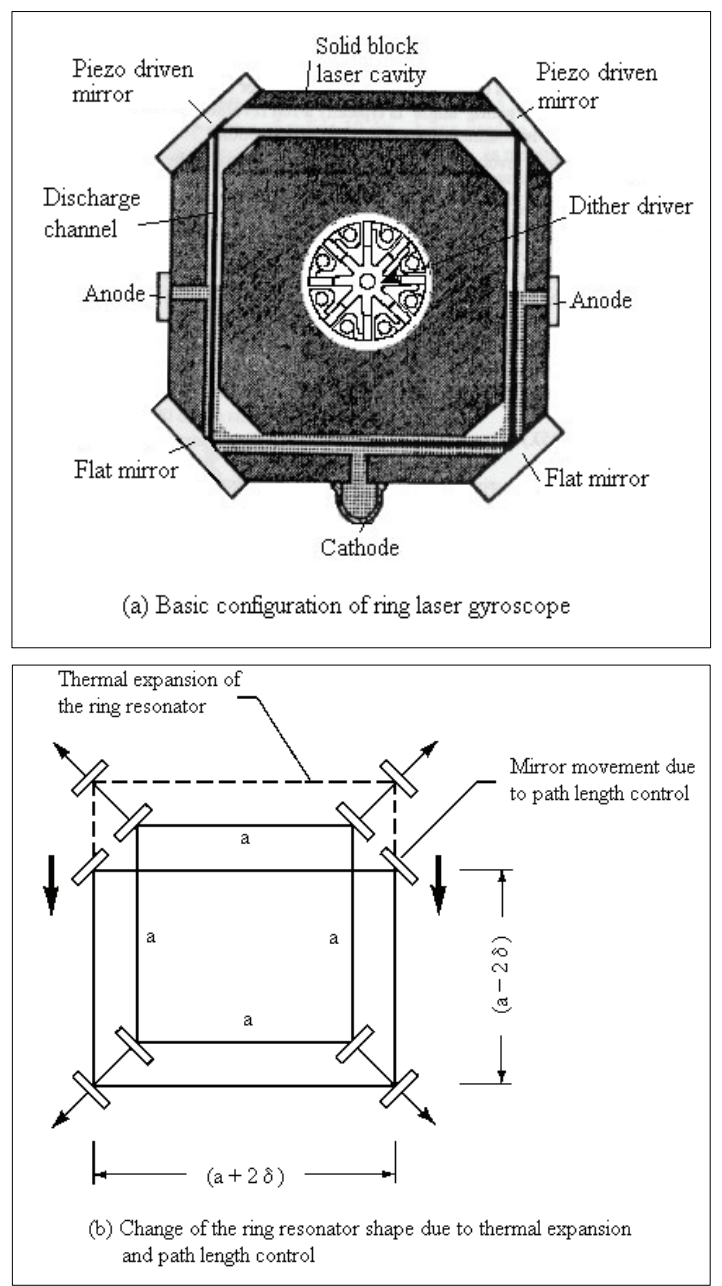

[Fig. 1] Basic configuration and Beam path geometry of ring laser gyroscope

where, $c$ : the light velocity in resonator, $v:$ the light wave frequency. 
If the resonator length changes, the frequency of the two wave trains will change too. Eq. (1) leads to

$$
\Delta v=(-) \frac{v^{2}}{m c} \Delta L=(-) \frac{v}{L} \Delta L
$$

Such a change of the resonator length can be reciprocal due to a mirror shift. Hence, it is very easy to stabilize the resonator length by means of piezo-driven moveable mirror, which is always put into position, where the output power of ring laser is at a maximum value. Even if the available regulating distance of the piezo transducer is not large enough to compensate the whole temperature variation, it should be rather easy to monitor the path length control. A temperature change will increase or decrease the lateral length of the square shown in Fig. 1-(b). The thermally induced distance variation is

$$
2 \delta=(L \Delta T \alpha) / 4
$$

where, $\Delta T:$ the temperature variation,

$\alpha$ : the linear thermal expansion coefficient

In order to stabilize the resonator length, two mirrors are shifted $4 \delta$. The scale factor becomes

$$
S c f=\frac{8 \pi A}{L \lambda}=\frac{8 \pi\left(a^{2}-4 \delta^{2}\right)}{L \lambda}=\frac{8 \pi A}{L \lambda}-\Delta
$$

where, $\Delta=\frac{1}{2} m \Delta T^{2} \alpha^{2}$ and the scale factor is the slope of input-output diagram for a certain rotation rate.

$$
\begin{aligned}
\dot{\psi} & =\Delta v 2 \pi=\frac{v}{L} \Delta L 2 \pi=\frac{v}{L}\left(\frac{4 A \Omega}{c}\right) 2 \pi \\
& =\frac{8 \pi A}{L(c / v)} \Omega
\end{aligned}
$$

The temperature change and thermal expansion of resonator block have an influence on the scale factor errors (instability and nonlinearity) which are mainly caused by the lock-in effect.

\section{Behavior of membrane relating with piezo-driven mirror}

\subsection{Behavior of piezo-driven mental membrane in bending}

The main deflection is due to the piezo-driven surface deformation in the radial direction. The deformations simultaneously occur at the inner and outer rims of a circular plate of piezo ceramic transducer. Thus, the radial strain $\varepsilon_{r}$ can be given by,

$$
\begin{aligned}
\varepsilon_{r}(r) & =\frac{1}{E}\left(\sigma_{r}-v \sigma_{\theta}\right) \\
= & \frac{1}{E} \frac{3 p_{0}}{8 t_{1}^{2}}\left(1-v^{2}\right)\left(R_{o}{ }^{2}-3 r^{2}\right)
\end{aligned}
$$

where

$$
\sigma_{r}=\frac{3 p_{0}}{8 t_{1}^{2}}\left[(1+v) R_{o}^{2}-(3+v) r^{2}\right]
$$

$$
\sigma_{\theta}=\frac{3 p_{0}}{8 t_{1}{ }^{2}}\left[(1+v) R_{o}{ }^{2}-(1+3 v) r^{2}\right]
$$

Since the deformation is distributed uniformly over the original length and the behavior of axisymmetric cross-section may be known to be a pure bending, the preceding expression about the bending center can yield the radial deformation of one side,

$$
\begin{aligned}
& \frac{1}{2}\left(\frac{\Delta L}{2}\right)=\int_{R_{i}}^{R_{o}} \varepsilon_{r}(r) d r \\
& \quad=\frac{3 p_{o}}{8 E t_{1}{ }^{2}}\left(1-v^{2}\right)\left(R_{o}{ }^{2} R_{i}-R_{i}{ }^{3}\right)
\end{aligned}
$$

where, $\Delta L$ : the deformation of diameter of circular piezo ceramic transducer,

$\Delta L / 2$ : the deformation of axisymmetric side of metal membrane,

$\Delta L / 4$ : the deformation of symmetric bending side 
From Eq. (8), the pressure due to the piezo ceramic transducer can be given by,

$$
p_{0}=\frac{2 E t_{1}{ }^{2}}{3\left(1-v^{2}\right)\left(R_{o}{ }^{2}-R_{i}{ }^{2}\right) R_{i}} \Delta L
$$

The maximum deflection of a piece occurs at the bending center, $r=R_{i}$,

$$
\begin{aligned}
& w_{\max }=\frac{\left(R_{o}{ }^{2}-R_{i}{ }^{2}\right)}{8 R_{i} t_{1}} \Delta L \\
& \text { where, } R_{i}=\left(R_{p_{-} o}+R_{p_{-} i}\right) / 2, R_{o}=R_{p_{-} o}
\end{aligned}
$$

Eq. (10-a) is the deflection of a half model of axisymmetric cross-section with respect to the bending center. The maximum deflection of metal membrane can be calculated by the superposition of Eq. (10-a).

$$
w_{1}=2 w_{\max }=\frac{\left(R_{o}^{2}-R_{i}^{2}\right)}{4 R_{i} t_{1}} \Delta L
$$

where, $R_{p_{-} i \text { and }} R_{p_{-} o}$ : respectively the radii of inner and outer rims

\subsection{Behavior of mirror membranes in bending}

By the action of the force $P$, all points of the mirror membrane 1 and 2 are displaced in the axial direction at a value of $w_{2}$ and $w_{3}$. We can define the stiffness of the membrane 1 and 2, from Eq. (5)

$$
\begin{aligned}
& g_{2}=\frac{P}{2 w_{2}}=\frac{64 \pi D_{2} R_{m 1_{-} i}{ }^{2}}{2\left(R_{m 1_{-} o}{ }^{2}-R_{m 1_{-} i}\right)^{2}} \\
& g_{4}=\frac{P}{w_{4}}=\frac{64 \pi D_{4} R_{m 2_{-} i}{ }^{2}}{\left(R_{m 2_{-} o}{ }^{2}-R_{m 2_{-} i}{ }^{2}\right)^{2}}
\end{aligned}
$$

\subsection{Behavior of mirror block(central post) in tension}

We can define the stiffness of the rod as a ratio of the axis lengthening force $P$ to it's elongation length $\Delta H$ caused by this force,

$$
g_{3}=\frac{P}{\Delta H}
$$

The full elongation of an infinitely thin layer having thickness $d z$ at a range of $z$ from lower surface is defined in accordance with the Hook's law,

$$
\begin{aligned}
\Delta H & =\int_{0}^{H} \frac{P}{A(z) E_{3}} d z=\frac{P}{E_{3}} \int_{0}^{H} \frac{d z}{A(z)} \\
& =\frac{P}{E_{3}}\left[\int_{0}^{h_{2}} \frac{d z}{A_{2}}+\int_{h_{2}}^{h_{1}+h_{2}} \frac{d z}{A_{1}}\right] \\
& =\frac{P}{E_{3}}\left[\frac{h_{2}}{\pi R_{r_{-} 2}{ }^{2}}+\frac{h_{1}}{\pi R_{r_{-}{ }^{2}}^{2}}\right]
\end{aligned}
$$

We found the value of the stiffness of a rod from ratio Eq. (12),

$$
g_{2}=\frac{E_{3} \pi\left(R_{r_{-} 1} R_{r_{-} 2}\right)^{2}}{R_{r_{-} 1}{ }^{2} h_{2}+R_{r_{-} 2}{ }^{2} h_{1}}
$$

When all parts of the assembly are deformed in equilibrium state, the metal membrane bends and through the rod, pushes or pulls the central part of the membrane. The internal forces of elastic nature are set up in the piezo-driven parts and these forces resist to the deflections of the piezo-driven parts. The parts of the assembly experience a deformation, so that a displacement of the membrane center is reduced, as compared with a free deformation of the center of piezo-driven part, by the values of elastic deformations of the piezo-driven part and the rod,

$$
w_{4}=w_{1}-w_{2}-w_{3}
$$

A deformation of the membrane 2 can be written as a function of the stiffness of piezo-driven parts, 


$$
w_{4}=\frac{w_{1}}{1+\frac{g_{4}}{g_{2}}+\frac{g_{4}}{g_{3}}}=\frac{\frac{\left(R_{o}{ }^{2}-R_{i}^{2}\right)}{4 R_{i} t_{1}} \Delta L}{1+\frac{g_{4}}{g_{2}}+\frac{g_{4}}{g_{3}}}
$$

where $p_{0}$ is an uniform pressure induced by the piezo-ceramic transducer on the metal membrane. $p_{o \text { occurs }}$ the free deformation of the metal membrane without any resistance of mirror membranes and central post.

\section{Simulation and discussion}

Fig. 2 shows the finite element model of piezo-driven mirror composed of 46530 solid elements for five parts. The boundary condition is the contact zone to resonator block which is restrained by three clamped translations.

The following dimensions and material properties in Table 1 are used for the numerical results;

$$
\begin{aligned}
& R_{o}=10.5 \mathrm{~mm}, R_{i}=6.5 \mathrm{~mm}, t_{1}=0.8 \mathrm{~mm}, \\
& R_{m 1_{-} i}=3.0 \mathrm{~mm}, R_{m 2_{-} o}=8.0 \mathrm{~mm}, t_{2}=0.7 \mathrm{~mm}, \\
& R_{m 2_{-} i}=3.3 \mathrm{~mm}, R_{m 2_{-} o}=6.8 \mathrm{~mm}, t_{4}=0.8 \mathrm{~mm}, \\
& R_{r_{-} 1}=3.0 \mathrm{~mm}, R_{r_{-} 2}=3.0 \mathrm{~mm}, h_{1}=h_{2}=3.2 \mathrm{~mm}
\end{aligned}
$$

The metal membrane and mirror parts are respectively made of INVAR 36 ALLOY and ZERODUR. The piezo-driven ( $\Delta L=2 \mu m$ ) pressure on the surface of metal membrane is calculated by Eq. (9), which is $p_{0}=0.29 \mathrm{MPa}$, and the maximum deflection of metal membrane $\left(w_{1}\right)$ is $6.53 \mu \mathrm{m}$.

From Eq. (16), the maximum deflection of the reflection mirror mounted on the mirror membrane 2 is given by $0.66 \mu \mathrm{m}$. And the MSC/NASTRAN v70.7 was adopted to calculate the deflection of finite element model. Fig. 3 shows the deformation contour of piezo-driven mirror, using the finite element analysis. The maximum deflection is shown in the surface on the metal membrane, and the deflection of reflection mirror is $0.63 \mu \mathrm{m}$. Compared the numerical result with the simulation, the deflection of reflection mirror has the error of $4.7 \%$. Thus, in the preliminary stage, the dimensions of piezo-driven mirror components can efficiently be designed by the theoretical equations.

[Table 1] Material properties of piezo mirror components

\begin{tabular}{|c|c|c|c|}
\hline & $\begin{array}{c}\rho \\
\left(10^{-9} \text { ton } / \mathrm{mm} 3\right)\end{array}$ & $\begin{array}{c}E \\
(\mathrm{GPa})\end{array}$ & $v$ \\
\hline ZERODUR & 2.53 & 90.3 & 0.243 \\
\hline $\begin{array}{c}\text { INVAR 36 } \\
\text { ALLOY }\end{array}$ & 8.05 & 141 & 0.294 \\
\hline
\end{tabular}

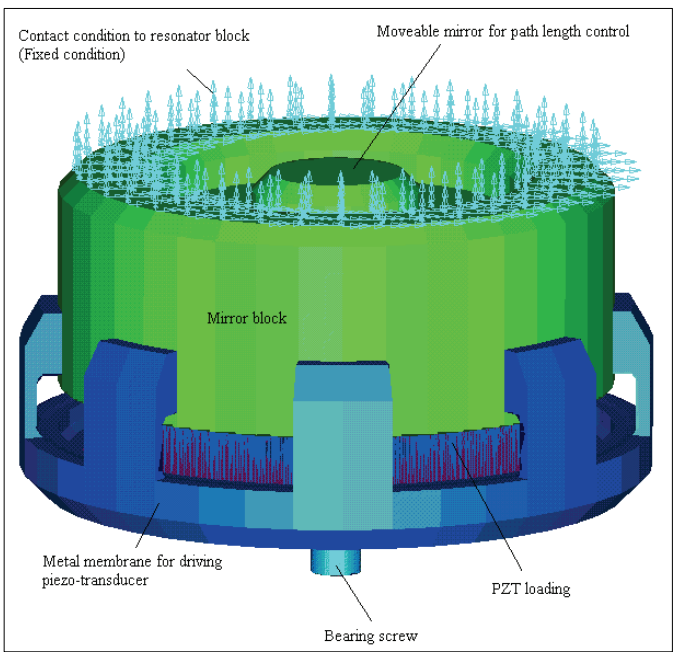

[Fig. 2] Finite element model of piezo-driven mirror

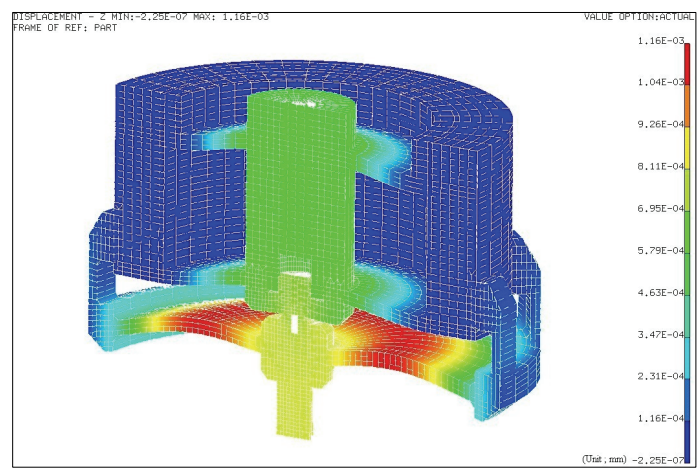

[Fig. 3] Deformation contour under PZT loading 


\section{Conclusions}

In the laser resonator, the scale factor instabilities and the lock-in threshold yielded a strong dependency on the beam path.

1. For the beam path control due to a piezo-driven mirror, this paper presents a theory of deflection of piezo-driven mirror as a function of the geometries and material properties of mirror components

2. In comparison with the simulation of finite element model, the theoretical result has the feasible error tolerance $(4.5 \%)$.

3. If the effective geometries on the base of deformation can be taken into account, the more precise result can be calculated. 4. Through the comparison, the presented theoretical approaches are known to be available.

\section{References}

[1] E.F. Ishchenko, "The analysis of an axial contour of the optical resonator", Journal of Applied Spectroscopy, Vol. 11, No. 3, pp. 456-463, 1969.

[2]Joseph T. Verdeyen, "Laser Electronics", Prentice-Hall Inc. 1981.

[3] Rudiger rodloff, "A laser gyro with optimized resonator geometry", IEEE Journal of Quantum Electronics, Vol. 23 , No. 4, pp. 438 - 445, 1987.

[4]C. Etrich, et. al, "Dynamics of a ring-laser gyroscope with backscattering", Physical review A, Vol.46, No.1 pp. 525-536, 1992.

[5] Ulrich K. Schreiber et. al, "Precision stabilization of the optical frequency in a large ring laser gyroscope", Applied Optics, Vol. 37, No. 36, pp. 8371 - 8381, 1998.

[6] Vetrov, A. A, "Calculation, fabrication, and study of waveguides for an integrated-optics gyroscope", Journal of optical technology, Vol.66, No.5 pp. 428, 1999.

[7] Stephen H. Crandall, Norman C. Dahl and Thomas J. Lardner, "An introduction to the mechanics of solids", McGraw-Hill, 2nd, New York, 1978.

[8] Ansel C. Ugural, Saul K. Fenster, "Advanced strength and applied elasticity", Prentice-Hall, 3rd edition, 1995.

[9] 이승표, 김광석, 고병갑, “전기보온밥솥 체결 구조물의 선 형 및 비선형 구조 해석”, Vol. 10, No. 3, pp. 493-499, 2009.

[10] 이종선, 백두순, “텐션 컨트롤러 스프링의 구조해 석”, Vol. 10, No. 1, pp.1-5, 2009.
Jeong-Ick Lee

[Regular member]

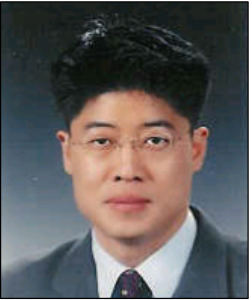

- Feb. 1991 : Hanyang Univ., Dept. of Mechanical Eng. (Bachelor)

- Feb. 1991 : Hanyang Univ., Dept. of Precision Mechanical Eng.(Master)

- Aug. 1999 : Hanyang Univ., Dept. of Precision Mechanical Eng.(Ph. D)

- Jan. $1993 \sim$ Dec. 1999 : Daewoo Electronics Co. (Senior Researcher)

- Mar. $2000 \sim$ Feb. 2007 : Yong-In Songdam College (Professor)

- Mar. $2007 \sim$ current : INHA Technical College (Professor)

$<$ Research Interests $>$

$\mathrm{CAD} / \mathrm{CAM} / \mathrm{CAE}$, Factroy Automation, Manufacturing Automation, Mold Injection, Ubiquitous, MEMS, Biomechanics 